\title{
Occurrence of Salmonella enterica and Escherichia coli in raw chicken and beef meat in northern Egypt and dissemination of their antibiotic resistance markers
}

\author{
Amira A. Moawad ${ }^{1,2}$, Helmut Hotzel $^{1}$, Omnia Awad $^{4}$, Herbert Tomaso ${ }^{1}$, Heinrich Neubauer ${ }^{1}$, Hafez M. Hafez ${ }^{5}$ \\ and Hosny El-Adawy ${ }^{1,3^{*}}$ (1)
}

\begin{abstract}
Background: The global incidence of foodborne infections and antibiotic resistance is recently increased and considered of public health concern. Currently, scarcely information is available on foodborne infections and ESBL associated with poultry and beef meat in Egypt.

Methods: In total, 180 chicken and beef meat samples as well as internal organs were collected from different districts in northern Egypt. The samples were investigated for the prevalence and antibiotic resistance of Salmonella enterica serovars and Escherichia coli. All isolates were investigated for harbouring class 1 and class 2 integrons.

Results: Out of 180 investigated samples 15 S. enterica (8.3\%) and 21 E. coli (11.7\%) were isolated and identified. S. enterica isolates were typed as 9 S. Typhimurium (60.0\%), 3 S. Paratyphi A (20.0\%), 2 S. Enteritidis (13.3\%) and 1 S. Kentucky (6.7\%). Twenty-one E. coli isolates were serotyped into 01, O18, O20, O78, O103, O119, 0126, O145, 0146 and 0158 . The phenotypic antibiotic resistance profiles of S. enterica serovars to ampicillin, cefotaxime, cefpodoxime, trimethoprim/sulphamethoxazole and tetracycline were 86.7, 80.0, 60.0, 53.3 and 40.0\%, respectively. Isolated E. coli were resistant to tetracycline (80.9\%), ampicillin (71.4\%), streptomycin, trimethoprim/sulphamethoxazole (61.9\% for each) and cefotaxime (33.3\%). The dissemination of genes coding for ESBL and AmpC $\beta$-lactamase in S. enterica isolates included bla $a_{\mathrm{CTX}-\mathrm{M}}(73.3 \%)$, bla $a_{\mathrm{TEM}}(73.3 \%)$ and bla $a_{\mathrm{CMY}}$ (13.3\%). In E. coli isolates bla $a_{\mathrm{TEM}}, b / a_{\mathrm{CTX}-\mathrm{M}}$ and bla $a_{\mathrm{OXA}}$ were identified in 52.4, 42.9 and $14.3 \%$, respectively. The plasmid-mediated quinolone resistance genes identified in $S$. enterica were qnrA (33.3\%), anrB (20.0\%) and qnrs (6.7\%) while gnrA and qnrB were detected in 33.3\% of E. coli isolates. Class 1 integron was detected in $13.3 \%$ of S. enterica and in $14.3 \%$ of E. coli isolates. Class 2 integron as well as the colistin resistance gene mcr-1 was not found in any of E. coli or S. enterica isolates.
\end{abstract}

Conclusions: This study showed high prevalence of S. enterica and E. coli as foodborne pathogens in raw chicken and beef meat in Nile Delta, Egypt. The emergence of antimicrobial resistance in S. enterica and E. coli isolates is of public health concern in Egypt. Molecular biological investigation elucidated the presence of genes associated with antibiotic resistance as well as class 1 integron in S. enterica and E. coli.

Keywords: Salmonella, Escherichia coli, Antibiotic resistance, Integron, Egypt

\footnotetext{
*Correspondence: hosny.eladawy@fli.de

${ }^{1}$ Friedrich-Loeffler-Institut, Institute of Bacterial Infections and Zoonoses,

Naumburger Str. 96a, 07743 Jena, Germany

Full list of author information is available at the end of the article
} 


\section{Background}

In spite of the improved technology and hygienic practices in developed countries at all stages of poultry and beef meat production, foodborne infections remain as a continuous threat to human and animal health. Escherichia (E.) coli and S. enterica serovars are the dominant members of Enterobacteriaceae causing foodborne infections. The expansion of antibiotic resistance in bacteria is also an emerging public health hazard due to the compromised efficacy in the treatment of infectious diseases [1].

The continuous exposure of bacterial strains by $\beta$-lactams has led to dynamic and massive production and mutation of $\beta$-lactamases [2]. Extended-spectrum $\beta$-lactamases (ESBLs) are derived from point mutations in the $b l a_{\mathrm{TEM}-1}$ and $b l a_{\mathrm{SHV}-1} \beta$-lactamase genes, which cannot hydrolyse cephamycins and are inhibited by clavulanic acid [3], while ampicillin class $C \beta$-lactamase $(A m p C)$ enzymes are active on cephamycins as well as oxyiminocephalosporins and monobactams [4]. ESBLs are mostly located on mobile genetic elements (plasmids or integrons), which can facilitate their mobility from bacterial species to others by horizontal gene transfer [5].

In Egypt, Salmonella isolates from chicken meat and organs showed high resistance to different antibiotic classes [6-8] where also, ESBL-producing E. coli were isolated from retail chicken meat and dairy products in Egypt $[9,10]$.

Quinolones considered as drugs of choice for treatment of human infections caused by Gram-negative bacteria. However, resistance to quinolones has been emerged over the time due to misuse and/or overdose of drugs in human and veterinary practice [11]. Plasmid-mediated quinolone resistance (PMQR) represented by quinolone resistance ( $q n r)$ genes is widely distributed among bacteria [12-14].

Integrons are genetic elements able to capture individual antibiotic resistance genes including $\beta$-lactamases encoding genes and stimulate their transcription and expression [15]. The capture and spread of antibiotic resistance determinants by integrons stimulates the rapid evolution of multidrug resistances (MDR) among Gramnegative bacteria [16]. Among five main integron classes, integrons 1 and 2 are most frequent in Gram-negative bacteria. More than 70 different antibiotic resistance genes have been characterized within integrons [16].

Colistin as antimicrobial substance was used against Gram-negative bacteria. Its usage has been limited due to its systemic toxicity but it was re-introduced as a last-line option in treatment of human infections [17, 18].

This study aimed to discuss the prevalence, serotyping, antibiotic resistance and characterization of resistance-associated genes in S. enterica serovars and E. coli isolated from beef and poultry meat products in the Nile Delta, Egypt.

\section{Methods}

\section{Sampling, isolation and identification of bacteria}

One hundred and eighty samples were randomly collected aseptically (90 chicken and 90 beef meat and organs) from slaughterhouses and markets in four districts in northern Egypt (Dakahlia, Damietta, Kafr ElSheikh and Gharbia governorates). Briefly, 30 samples of freshly slaughtered chickens and 30 samples of native frozen chickens from restaurants and supermarkets (each 15 from breast and from thigh muscles and skin) were taken. Thirty samples of organs (gizzard and liver) were collected from freshly slaughtered chickens. In addition, 30 beef meat samples of freshly slaughtered carcasses (neck, brisket, flank and rump muscles) were obtained from slaughterhouses. Thirty samples from locally frozen beef meat, collected from supermarkets and restaurants and 30 samples from organs (liver, spleen and heart) from freshly slaughtered animals were used in this study (Tables 1, 2).

Ten grams of each meat and organ sample were incised using sterile scalpel and forceps, transported immediately to the laboratory in ice bags, then transferred into sterile homogenizer flask containing $45 \mathrm{ml}$ of nutrient broth (Oxoid, Manchester, UK). The mixture was

Table 1 Sources, number of S. enterica isolates and results of their serovar identification

\begin{tabular}{|c|c|c|c|c|c|c|c|c|c|}
\hline \multirow[t]{2}{*}{ Serovar } & \multicolumn{4}{|l|}{ Poultry } & \multicolumn{4}{|l|}{ Beef } & \multirow{2}{*}{$\begin{array}{l}\text { (Poultry + beef) } \\
\text { n (\%) }\end{array}$} \\
\hline & $\begin{array}{l}\text { Fresh meat } \\
(n=30)\end{array}$ & $\begin{array}{l}\text { Frozen meat } \\
(n=30)\end{array}$ & $\begin{array}{l}\text { Fresh organs } \\
(n=30)\end{array}$ & $\begin{array}{l}\text { Total } \\
\text { n (\%) }\end{array}$ & $\begin{array}{l}\text { Fresh meat } \\
(n=30)\end{array}$ & $\begin{array}{l}\text { Frozen meat } \\
(n=30)\end{array}$ & $\begin{array}{l}\text { Fresh organs } \\
(n=30)\end{array}$ & $\begin{array}{l}\text { Total } \\
\text { n (\%) }\end{array}$ & \\
\hline S. Typhimurium & 2 & 0 & 1 & $3(3.3)$ & 3 & 1 & 2 & $6(6.7)$ & $9(60.0)$ \\
\hline S. Paratyphi A & 0 & 1 & 1 & $2(6.7)$ & 0 & 0 & 1 & $1(3.3)$ & $3(20.0)$ \\
\hline S. Enteritidis & 1 & 0 & 0 & $1(3.3)$ & 1 & 0 & 0 & $1(3.3)$ & $2(13.3)$ \\
\hline S. Kentucky & 1 & 0 & 0 & $1(3.3)$ & 0 & 0 & 0 & $0(0)$ & $1(6.7)$ \\
\hline Total & 4 & 1 & 2 & $7(7.8)$ & 4 & 1 & 3 & $8(8.8)$ & $15(100)$ \\
\hline
\end{tabular}


Table 2 Sources, number of $E$. coli isolates and results of their serogroup identification

\begin{tabular}{|c|c|c|c|c|c|c|c|c|}
\hline Serogroup & $\begin{array}{l}\text { Fresh poultry } \\
\text { meat } \\
(n=30)\end{array}$ & $\begin{array}{l}\text { Frozen poultry } \\
\text { meat } \\
(n=30)\end{array}$ & $\begin{array}{l}\text { Fresh poultry } \\
\text { organs } \\
(n=30)\end{array}$ & $\begin{array}{l}\text { Fresh beef } \\
\text { meat } \\
(n=30)\end{array}$ & $\begin{array}{l}\text { Frozen beef } \\
\text { meat } \\
(n=30)\end{array}$ & $\begin{array}{l}\text { Fresh beef } \\
\text { organs } \\
(n=30)\end{array}$ & $\begin{array}{l}\text { Total number } \\
\text { of isolates }\end{array}$ & $\begin{array}{l}\% \text { of } E \text {. coli } \\
\text { isolates }\end{array}$ \\
\hline 01 & 1 & 1 & 0 & 0 & 0 & 0 & 2 & 9.5 \\
\hline 018 & 2 & 1 & 1 & 0 & 0 & 0 & 4 & 19 \\
\hline $\mathrm{O} 20$ & 1 & - & 1 & - & - & - & 2 & 9.5 \\
\hline O78 & 1 & 0 & 0 & 1 & 1 & 1 & 4 & 19 \\
\hline 0103 & 0 & 0 & 0 & 0 & 1 & 0 & 1 & 4.8 \\
\hline 0119 & 1 & - & - & 1 & - & - & 2 & 9.5 \\
\hline 0126 & 0 & 0 & 1 & 0 & 1 & 0 & 2 & 9.5 \\
\hline 0145 & 0 & 0 & 1 & 0 & 0 & 0 & 1 & 4.8 \\
\hline 0146 & 0 & 1 & 0 & 0 & 0 & 0 & 1 & 4.8 \\
\hline 0158 & 0 & 0 & 0 & 1 & 1 & 0 & 2 & 9.5 \\
\hline Total & 6 & 3 & 4 & 3 & 4 & 1 & 21 & 100 \\
\hline
\end{tabular}

allowed to stand for $15 \mathrm{~min}$ at room temperature. From each sample, $1 \mathrm{ml}$ was added to $9 \mathrm{ml}$ of buffered peptone water (Oxoid) for E. coli cultivation and $9 \mathrm{ml}$ of Rappaport-Vassiliadis broth (Oxoid) for S. enterica isolation. After aerobic incubation at $37{ }^{\circ} \mathrm{C}$ overnight, a loopful from Rappaport-Vassiliadis broth was streaked on xylose lysine deoxycholate (XLD) agar (Oxoid) and from buffered peptone water on eosin methylene blue (EMB) agar (Oxoid). The inoculated plates were incubated aerobically at $37{ }^{\circ} \mathrm{C}$ for $18-24 \mathrm{~h}$. Suspected colonies were identified biochemically using API 20E (bioMérieux, Marcy-l'Étoile, France).

All biochemically confirmed Salmonella isolates were serotyped on the basis of somatic $(\mathrm{O})$ and flagellar $(\mathrm{H})$ antigens by slide agglutination test using commercial antisera (SIFIN, Berlin, Germany) following KauffmanWhite scheme [19]. Serological identification of E. coli was carried out using slide agglutination method using commercial antisera (SIFIN). The serotyping was carried out at the Serology Unit, Animal Health Research Institute, Dokki, Egypt, and the Bacteriology Laboratory, Central Laboratories of Ministry of Health, Cairo, Egypt.

\section{DNA extraction and purification}

The identified bacterial cultures were cultivated in LuriaBertani (LB) broth (Oxoid) at $37{ }^{\circ} \mathrm{C}$ overnight. DNA was extracted and purified using DNeasy Blood and Tissue Kits (Qiagen, Manchester, UK) according to the manufacturer's instructions.

\section{Molecular identification of S. enterica serovars and $E$. coli}

The isolated strains were further identified as S. enterica and E. coli using PCR assays. The amplification targets and primers (Eurofins, Yokohama, Japan) are listed in
Table 3. All phenotypically identified S. enterica serovars were tested for harbouring $\operatorname{ompC}$ gene. Isolated $E$. coli were confirmed by species-specific PCR targeting the 16S $r$ RNA genes and resulting in a $585 \mathrm{bp}$ amplicon. PCR assays used in this study resulted in Salmonella, S. Enteritidis and $S$. Typhimurium specific products of 204, 304 and 401 bp length, respectively.

The PCR protocol consisted of the following steps: (i) an initial denaturation step of $2 \mathrm{~min}$ at $95^{\circ} \mathrm{C}$; (ii) 30 cycles with 1 cycle consisting of $1 \mathrm{~min}$ at $95^{\circ} \mathrm{C}, 1 \mathrm{~min}$ at $57^{\circ} \mathrm{C}$, and $2 \mathrm{~min}$ at $72{ }^{\circ} \mathrm{C}$; and (iii) a final elongation step of 5 min at $72{ }^{\circ} \mathrm{C}$.

Five-microliter aliquots of reaction mixture were run in electrophoreses using 1.5\% agarose gels (Nippon Gene, Tokyo, Japan) and visualized under UV light after ethidium bromide staining.

\section{Determination of antimicrobial susceptibility profiles}

The antimicrobial susceptibility was determined using the Kirby-Bauer disc diffusion test [20]. Briefly, one colony picked up, streaked on Mueller-Hinton blood agar (Oxoid) and incubated at $37{ }^{\circ} \mathrm{C}$ overnight. Bacterial colonies were suspended in $0.9 \% \mathrm{NaCl}$ to obtain a McFarland turbidity of 0.5 (Dr. Lange, photometer CADAS 30, Berlin, Germany) containing $1-2 \times 10^{8}$ colony-forming units (CFU)/ml of E. coli strain ATCC 25922. Three hundred $\mu \mathrm{l}$ of the suspension were spread onto the surface of a Mueller-Hinton agar plate (Oxoid) using a sterile swab. The antimicrobial discs (Oxoid) of thirteen clinically used antibiotics, which are used in the Egyptian poultry and cattle farms (Tables 4,5 ) were distributed onto the surface of the Mueller-Hinton agar plates using a multi-disc dispenser (Oxoid). The plates were incubated at $37{ }^{\circ} \mathrm{C}$ overnight. The diameters of inhibition zones were measured using sliding calipers and interpreted using standard 
Table 3 PCR primers, their sequences and amplification targets used in this study

\begin{tabular}{|c|c|c|c|c|}
\hline Primer & Sequence $\left(5^{\prime}-3^{\prime}\right)$ & Amplicon size (bp) & Amplification target & References \\
\hline \multicolumn{5}{|c|}{ E. coli, Salmonella enterica and Salmonella serovar identification } \\
\hline ECO-f & GAC CTC GGT TTA GTT CAC AGA & 585 & E. coli & {$[67]$} \\
\hline ECO-r & CAC ACG CTG ACG CTG ACC A & & & \\
\hline OMPCF & ATC GCT GAC TTA TGC AAT CG & 204 & Salmonella genus & {$[68]$} \\
\hline OMPCR & CGG GTT GCG TTA TAG GTC TG & & & \\
\hline ENTF & TGT GTT TTA TCT GAT GCA AGA GG & 304 & S. Enteritidis & {$[68]$} \\
\hline ENTR & TGA ACT ACG TTC GTT CTT CTG G & & & \\
\hline TYPHF & TTG TTC ACTTTTTAC CCC TGA A & 401 & S. Typhimurium & {$[68]$} \\
\hline TYPHR & CCC TGA CAG CCG TTA GAT ATT & & & \\
\hline \multicolumn{5}{|c|}{$\beta$-Lactamases } \\
\hline TEM-F & ATA AAA TTC TTG AAG ACG AAA & 1080 & $b / a_{\mathrm{TEM}}$ & {$[69]$} \\
\hline TEM-R & GAC AGT TAC CAA TGC TTA ATC & & & \\
\hline OXA-F & TCA ACT TTC AAG ATC GCA & 591 & $b / a_{\mathrm{OXA}}$ & {$[69]$} \\
\hline OXA-R & GTG TGT TTA GAA TGG TGA & & & \\
\hline OXA-F-2 & ATT AAG CCC TTT ACC AAA CCA & & Whole bla OXA & {$[69]$} \\
\hline OXA-R-2 & AAG GGT TGG GCG ATT TTG CCA & & & \\
\hline OXA-23-F & GAT CGG ATT GGA GAA CCA GA & 501 & $b / a_{\text {OXA-23 }}$ & {$[25]$} \\
\hline OXA-23-R & ATT TCT GAC CGC ATT TCC AT & & & \\
\hline CTX-M-F & CGC TTT GCG ATG TGC AG & 550 & $b / a_{\mathrm{CTX}-\mathrm{M}}$ & {$[69]$} \\
\hline CTX-M-R & ACC GCG ATA TCG TTG GT & & & \\
\hline CTX-M-F2 & CCA GAA TAA GGA ATC CCA TG & & Whole bla $a_{C T X-M}$ & {$[69]$} \\
\hline CTX-M-R2 & GCC GTC TAA GGC GAT AAA C & & & \\
\hline CMY-F & GAC AGC CTC TTT CTC CAC A & 1007 & $b l a_{\mathrm{CMY}}$ & {$[69]$} \\
\hline CMY-R & TGG AAC GAA GGC TAC GTA & & & \\
\hline CMY-F2 & ACG GAA CTG ATT TCA TGA TG & & Whole bla ${ }_{\mathrm{CMY}}$ & {$[69]$} \\
\hline CMY-R2 & GAA AGG AGG CCC AAT ATC CT & & & \\
\hline SHV-F & TTA TCT CCC TGT TAG CCA CC & 795 & $b / a_{\mathrm{SHV}}$ & {$[69]$} \\
\hline $\mathrm{SHV}-\mathrm{R}$ & GAT TTG CTG ATTTCG CTC GG & & & \\
\hline \multicolumn{5}{|l|}{ Integrons } \\
\hline $5^{\prime}-\mathrm{CS}$ & GGC ATC CAA GCA GCA AG & 152 & Class 1 integron & {$[69]$} \\
\hline $3^{\prime}-\mathrm{CS}$ & AAG CAG ACT TGA CCT GA & & & \\
\hline hep74 & CGG GAT CCC GGA CGG CAT GCA CGA TTT GTA & 491 & Class 2 integron & {$[69]$} \\
\hline hep51 & GAT GCC ATC GCA AGT ACG AG & & & \\
\hline \multicolumn{5}{|c|}{ Plasmid-mediated quinolone resistance gene } \\
\hline qnrA-F & ATT TCT CAC GCC AGG ATT TG & 516 & qnrA & {$[69]$} \\
\hline qnrA-R & GAT CGG CAA AGG TTA GGT CA & & & \\
\hline qnrB-F & GAT CGT GAA AGC CAG AAA GG & 469 & anrB & {$[69]$} \\
\hline qnrB-R & ACG ATG CCT GGT AGT TGT CC & & & \\
\hline qnrS-F & ACG ACA TTC GTC AAC TGC AA & 417 & anrs & {$[69]$} \\
\hline qnrS-R & TAA ATT GGC ACC CTG TAG GC & & & \\
\hline \multicolumn{5}{|c|}{ Plasmid-mediated colistin resistance gene } \\
\hline CLR5-F & CGG TCA GTC CGTTTG TTC & 308 & $m c r-1$ & {$[24]$} \\
\hline CLR5-R & CTT GGT CGG TCT GTA GGG & & & \\
\hline
\end{tabular}




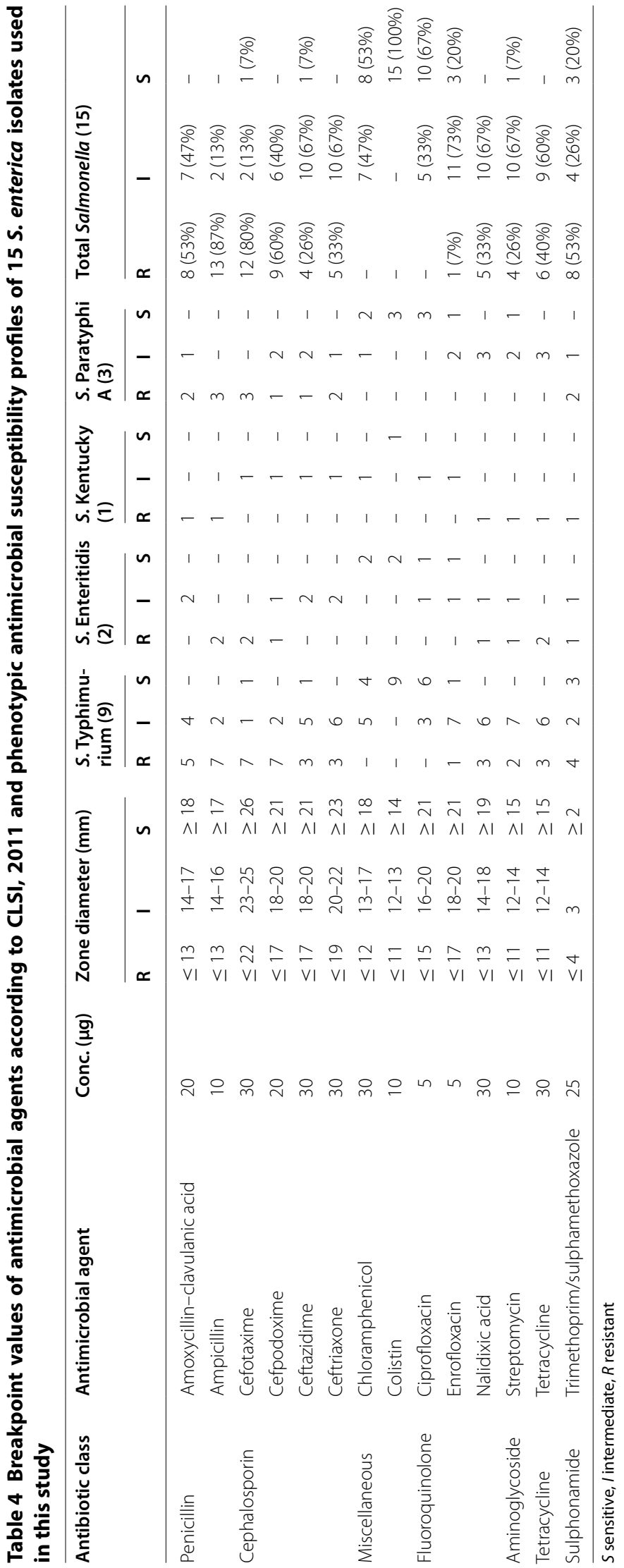


Table 5 Breakpoint values of antimicrobial agents according to CLSI, 2011 and phenotypic antimicrobial susceptibility profiles of $E$. coli isolates used in this study

\begin{tabular}{|c|c|c|c|c|c|c|c|c|c|c|c|c|c|c|c|c|c|}
\hline \multirow[t]{3}{*}{ Antibiotic class } & \multirow[t]{3}{*}{ Antimicrobial agent } & \multirow[t]{3}{*}{ Conc. $(\mu \mathrm{g})$} & \multirow{2}{*}{\multicolumn{3}{|c|}{ Zone diameter (9) }} & \multicolumn{9}{|c|}{ E. coli (21) } & \multicolumn{3}{|c|}{ Resistance rate } \\
\hline & & & & & & \multicolumn{3}{|c|}{$\begin{array}{l}\text { Poultry } \\
\text { (15) }\end{array}$} & \multicolumn{3}{|c|}{ Beef (6) } & \multicolumn{3}{|c|}{ Total (21) } & \multirow{2}{*}{$\begin{array}{l}\text { Poultry } \\
\%\end{array}$} & \multirow{2}{*}{$\begin{array}{l}\text { Beef } \\
\%\end{array}$} & \multirow{2}{*}{$\begin{array}{l}\text { Total } \\
\%\end{array}$} \\
\hline & & & $\mathbf{R}$ & I & $S$ & $\mathbf{R}$ & 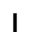 & $\mathrm{S}$ & $\mathbf{R}$ & 1 & $S$ & $\mathbf{R}$ & $\mathbf{I}$ & $\mathrm{S}$ & & & \\
\hline \multirow[t]{2}{*}{ Penicillin } & Amoxycillin-clavulanic acid & 20 & $\leq 13$ & $14-17$ & $\geq 18$ & 10 & 4 & 1 & 3 & 3 & - & 13 & 7 & 1 & 66.7 & 50.0 & 61.9 \\
\hline & Ampicillin & 10 & $\leq 13$ & $14-16$ & $\geq 17$ & 12 & 2 & 1 & 3 & 3 & - & 15 & 5 & 1 & 80.0 & 50.0 & 71.4 \\
\hline \multirow[t]{4}{*}{ Cephalosporin } & Cefotaxime & 30 & $\leq 22$ & $23-25$ & $\geq 26$ & 6 & 7 & 2 & 1 & 3 & 2 & 7 & 10 & 4 & 40.0 & 16.7 & 33.3 \\
\hline & Cefpodoxime & 20 & $\leq 17$ & $18-20$ & $\geq 21$ & 3 & 12 & - & 2 & 4 & - & 5 & 16 & - & 20.0 & 33.3 & 23.8 \\
\hline & Ceftazidime & 30 & $\leq 17$ & $18-20$ & $\geq 21$ & 5 & 9 & 1 & - & 6 & - & 5 & 15 & 1 & 33.3 & 0 & 23.8 \\
\hline & Ceftriaxone & 30 & $\leq 19$ & $20-22$ & $\geq 23$ & 3 & 5 & 7 & 1 & 3 & 2 & 4 & 8 & 9 & 20.0 & 16.7 & 19.0 \\
\hline \multirow[t]{2}{*}{ Miscellaneous } & Chloramphenicol & 30 & $\leq 12$ & $13-17$ & $\geq 18$ & 3 & 9 & 3 & 1 & 1 & 4 & 4 & 10 & 7 & 20.0 & 16.7 & 19.0 \\
\hline & Colistin & 10 & $\leq 11$ & $12-13$ & $\geq 14$ & - & 1 & 14 & - & - & 6 & - & 1 & 20 & - & - & - \\
\hline \multirow[t]{3}{*}{ Fluoroquinolone } & Ciprofloxacin & 5 & $\leq 15$ & $16-20$ & $\geq 21$ & 4 & 3 & 8 & 2 & 2 & 2 & 6 & 5 & 10 & 26.7 & 33.3 & 28.6 \\
\hline & Enrofloxacin & 5 & $\leq 17$ & $18-20$ & $\geq 21$ & 2 & 5 & 8 & 1 & 4 & 1 & 3 & 9 & 9 & 13.3 & 16.7 & 14.3 \\
\hline & Nalidixic acid & 30 & $\leq 13$ & $14-18$ & $\geq 19$ & 5 & 12 & 3 & 1 & 2 & 3 & 6 & 14 & 6 & 33.3 & 16.7 & 28.6 \\
\hline Aminoglycoside & Streptomycin & 10 & $\leq 11$ & $12-14$ & $\geq 15$ & 9 & 5 & 1 & 4 & 2 & - & 13 & 7 & 1 & 60.0 & 66.7 & 61.9 \\
\hline Tetracycline & Tetracycline & 30 & $\leq 11$ & $12-14$ & $\geq 15$ & 12 & 3 & - & 5 & 1 & - & 17 & 4 & - & 80.0 & 83.3 & 81.0 \\
\hline Sulphonamide & Trimethoprim/sulphamethoxazole & 25 & $\leq 4$ & 3 & $\geq 2$ & 10 & 2 & 3 & 3 & - & 3 & 17 & 2 & 6 & 66.7 & 50.0 & 81.0 \\
\hline
\end{tabular}

$S$ sensitive, I intermediate, $R$ resistant

break points according to Clinical and Laboratory Standards Institute [21].

The antimicrobial susceptibility of colistin was determined by disc diffusion susceptibility testing using colistin discs (Oxoid) containing $10 \mu \mathrm{g}$. The disc zone diameters was interpreted according to previous report [22].

\section{Molecular detection of antimicrobial resistance associated genes}

Escherichia coli and S. enterica isolates were tested for $\beta$-lactamase-encoding genes $b l a_{\mathrm{TEM}}, b l a_{\mathrm{SHV}}, b l a_{\mathrm{CTX}-\mathrm{M}}$, $b l a_{\mathrm{OXA}}$ and $b l a_{\mathrm{CMY}}$ by PCR using universal primers for the corresponding gene families (Table 3) as described previously [23]. PCR amplification was also used for screening of plasmid-mediated quinolone resistance genes $q n r \mathrm{~A}, q n r \mathrm{~B}$ and $q n r \mathrm{~S}$.

For detection of variants of $b l a_{\mathrm{TEM}}, b l a_{\mathrm{SHV}}, b l a_{\mathrm{CTX}-\mathrm{M}}$, $b l a_{\mathrm{OXA}}$ and $b l a_{\mathrm{CMY}}$ amplified PCR fragments were purified from agarose gels using Nucleospin Gel Extraction Kit (Macherey-Nagel, Düren, Germany). The products were sequenced and the sequencing results were analyzed using BLAST (http://blast.ncbi.nlm.nih.gov/blast.cgi).

Colistin resistance associated gene $m c r-1$ was identified using a PCR assay (Table 3) as described by Liu et al. [24]. PCR for detection of carbapenemases blaOXA-23 gene was performed using OXA-23-F and OXA-23-R
(Table 3). PCR reaction and conditions were performed according to Braun et al. [25].

Detection and sequencing of class 1 and class 2 integrons PCR assays for detection of class 1 and class 2 integrons were performed using primers given in Table 3 and yielded PCR fragments that were purified from agarose gels using Nucleospin Gel Extraction Kit (MachereyNagel, Düren, Germany). The products were sequenced in Genome Centre, Gifu University, Japan. The sequencing results were analyzed using BLAST (http://blast.ncbi. nlm.nih.gov/blast.cgi).

\section{Results}

Out of 180 examined samples 15 S. enterica (8.3\%) (7 from poultry and 8 from beef) (Table 1) as well as $21 E$. coli $(11.7 \%)$ (15 from poultry and 6 from beef) (Table 2) were isolated and identified using bacteriological methods and biochemical characterization.

\section{Serological characterization of S. enterica and E. coli}

Fifteen isolated S. enterica were typed as 9 S. enterica serovar Typhimurium (60.0\%; 3 from chicken and 6 from beef), 3 S. enterica Paratyphi A (20.0\%; 2 from chickens and 1 from beef), 2 S. enterica serovar Enteritidis (13.3\%; 1 from chicken and 1 from beef) and 1 S. enterica serovar Kentucky (6.7\%) from chicken sample (Table 1). 
Twenty-one $E$. coli isolates were characterized as $4 \mathrm{O} 18$ (19.0\%) and 4 O78 (19.0\%) serotypes. Other serotypes are given in Table 2.

\section{Molecular identification of Salmonella serovars}

All 15 recovered S. enterica serovars harboured ompC gene, which confirms Salmonella genus. Nine S. enterica serovar Typhimurium (60.0\%) and two S. enterica serovar Enteritidis (13.3\%) were identified by means of serovarspecific bands using PCR (Table 3). Four other isolates could not be typed with PCR method (26.7\%).

\section{Determination of antimicrobial susceptibility profiles}

The results of determination of antimicrobial resistance of $S$. enterica and E. coli isolates to thirteen antibiotics are given in Tables 4 and 5. Most of the S. enterica isolates showed resistance to ampicillin (87.0\%) and cefotaxime (80.0\%) and all were susceptible to chloramphenicol, colistin and ciprofloxacin. Resistance to other antibiotics was shown in Table 4.

Seven isolates of $S$. enterica serovar Typhimurium were resistant to ampicillin, cefotaxime and cefpodoxime (77.8\%), while 6 isolates (66.7\%) were highly sensitive to ciprofloxacin. Resistance to other antibiotics was weaker developed.

Both S. enterica serovar Enteritidis isolates were resistant to ampicillin, cefotaxime and tetracycline. Additionally, one isolate showed resistance to streptomycin, nalidixic acid, trimethoprim/sulphamethoxazole and streptomycin.
In addition to the entire resistance to ampicillin and cefotaxime, majority of the S. enterica serovar Paratyphi A isolates were resistant to amoxicillin-clavulanic acid, ceftriaxone and trimethoprim/sulphamethoxazole.

Salmonella enterica serovar Kentucky isolate showed no pronounced susceptibility to any of the tested antibiotics and was resistant to six of them (Table 4). Seven out of 15 S. enterica serovars (46.7\%) revealed phenotypic multidrug resistance exhibiting by resistance to three or more classes of antibiotics (Table 4).

Escherichia coli isolates showed resistance to tetracycline, ampicillin, streptomycin, trimethoprim/sulphamethoxazole and amoxicillin-clavulanic acid with $80.9,71.4,61.9,61.9$ and $61.9 \%$, respectively. Ten (47.6\%), $9(42.8 \%)$ and $9(42.8 \%)$ isolates were susceptible to ciprofloxacin, enrofloxacin and ceftriaxone, respectively. All tested isolates were susceptible to colistin. Thirteen E. coli isolates $(61.9 \%)$ were characterized as multidrug resistant (Table 5).

The multidrug resistance of isolated Salmonella and $E$. coli was shown in Tables 6 and 7, respectively.

\section{Molecular detection of resistance-associated genes}

Six of 8 screened resistance-associated genes were detected in S. enterica serovars by PCR (Table 6). Eleven $(73.3 \%)$ isolates harboured $b l a_{\text {CTX-M }}$ gene (1, 3 and 14$)$ associated with cefotaxime resistance and 11 (73.3\%) isolates harboured $b l a_{\mathrm{TEM}-1}$ gene associated with penicillin and narrow spectrum $\beta$-lactamase resistance. Five $(33.3 \%)$ isolates harboured quinolone resistance gene

Table 6 Phenotypic resistance and resistance determinants found in S. enterica isolates in this study

\begin{tabular}{|c|c|c|c|}
\hline Source & Serovar & Resistance phenotype & Resistance genes/class 1 integrons \\
\hline \multicolumn{4}{|l|}{ Poultry } \\
\hline Fresh poultry meat & Typhimurium & CPD, CTX, NAL & $b l a_{\mathrm{CTX}-\mathrm{M}-1}, q n r \mathrm{~A}, q n r \mathrm{~B}$, anrS \\
\hline Fresh poultry meat & Typhimurium & AMC, AMP, CPD & $b / a_{\mathrm{TEM}-1}$ \\
\hline Fresh poultry meat & Enteritidis & AMP, CTX, TET & $b / a_{\mathrm{CTX}-\mathrm{M}-1}, b / a_{\mathrm{TEM}-1}$ \\
\hline Fresh poultry meat & Kentucky & AMC, AMP, NAL, STR, TET, T/S & $b l a_{\mathrm{TEM}-1}, q n r \mathrm{~A}$ \\
\hline Fresh poultry organs (liver) & Typhimurium & AMC, AMP, CPD, CRO, CTX, NAL, T/S & $b l a_{\mathrm{CTX}-\mathrm{M}-1}, b l a_{\mathrm{TEM}-1}$, anrA, dfrA15, dfrA17 \\
\hline Fresh poultry organs (liver) & Paratyphi A & AMC, AMP, CAZ CRO, CTX, T/S & $b / a_{\mathrm{CTX}-\mathrm{M}-14}, b / a_{\mathrm{TEM}-1}$ \\
\hline Frozen poultry meat & Paratyphi A & AMC, AMP, CRO, CTX, T/S & $b / a_{\mathrm{CTX}-\mathrm{M}-14}, b / a_{\mathrm{TEM}-1}$ \\
\hline \multicolumn{4}{|l|}{ Beef } \\
\hline Fresh beef meat & Typhimurium & AMP, CAZ, CTX & $b l a_{\mathrm{CTX}-\mathrm{M}-1}$ \\
\hline Fresh beef meat & Typhimurium & AMP, CAZ, CRO, CTX & $b / a_{\mathrm{CTX}-\mathrm{M}-1}$ \\
\hline Fresh beef meat & Typhimurium & AMC, CPD, CTX, TET, T/S & $b l a_{\mathrm{CTX}-\mathrm{M}-3}, b l a_{\mathrm{TEM}-1}$ \\
\hline Fresh beef meat & Enteritidis & AMP, CPD, CTX, NAL, STR, TET, T/S & $b l a_{\mathrm{CMY}-2}, b l a_{\mathrm{CTX}-\mathrm{M}-1}, b a_{\mathrm{TEM}-1}, a n r \mathrm{~A}$, anrB \\
\hline Fresh beef organs (spleen) & Typhimurium & AMP, CPD, CTX, STR,TET, T/S & $b / a_{\mathrm{CTX}-\mathrm{M}-14}, b / a_{\mathrm{TEM}-1}$ \\
\hline Fresh beef organs (liver) & Typhimurium & AMC, AMP, CPD & - \\
\hline Fresh beef organs (liver) & Paratyphi A & AMP, CPD, CTX & $b / a_{\mathrm{TEM} 1}$ \\
\hline Frozen beef meat & Typhimurium & AMC, AMP, CAZ, CPD, CRO, CTX, ENR, NAL, STR, TET, T/S & $b l a_{\mathrm{CMY}-2}, b l a_{\mathrm{CTX}-\mathrm{M}-1}, b l a_{\mathrm{TEM} 1}, a n r \mathrm{~A}$, anrB, aadA2 \\
\hline
\end{tabular}

AMC amoxycillin-clavulanic acid, AMP ampicillin, CAZ ceftazidime, CPD cefpodoxime, CRO chloramphenicol, CTX cefotaxime, ENR enrofloxacin, NAL nalidixic acid, STR streptomycin, TET tetracycline, $T / S$ trimethoprim/sulphamethoxazole 
Table 7 Phenotypic resistance and resistance determinants found in $E$. coli isolates in this study

\begin{tabular}{|c|c|c|c|}
\hline Source & E. coli serotype & Resistance phenotype & Resistance genes/class 1 integron \\
\hline \multicolumn{4}{|l|}{ Poultry } \\
\hline Fresh poultry meat & 01 & STR, TET & - \\
\hline Fresh poultry meat & 018 & AMP, CIP, CPD, NAL, STR, TET, T/S & qnrA, anrB \\
\hline Fresh poultry meat & 018 & AMC, AMP, CHL, CIP, CRO, CTX, NAL, STR, TET, T/S & $b l a_{\mathrm{CTX}-\mathrm{M}-1}, b l a_{\mathrm{OXA}-1}, a n r \mathrm{~A}, a n r \mathrm{~B}$ \\
\hline Fresh poultry meat & O78 & AMC, AMP, CAZ, TET, T/S & $b l a_{\text {CTX-M-1 }}, b l a_{\text {TEM-1 }}$ \\
\hline Fresh poultry meat & 0119 & AMC, AMP, CAZ, CTX, STR, TET, T/S & $b l a_{\mathrm{CTX}-\mathrm{M}-14}, b / a_{\mathrm{TEM}-104}$ \\
\hline Fresh poultry meat & $\mathrm{O} 20$ & $\mathrm{AMC}, \mathrm{AMP}, \mathrm{CPD}, \mathrm{TET}, \mathrm{T} / \mathrm{S}$ & $b l a_{\mathrm{CTX}-\mathrm{M} 1}, b l a_{\mathrm{OXA}-1}, b l a_{\mathrm{TEM}-1}$ \\
\hline Fresh poultry organs (liver) & 018 & $\begin{array}{l}\text { AMC, AMP, CAZ, CHL, CIP, CRO, CTX, ENR, NAL, STR, } \\
\text { TET, T/S }\end{array}$ & bla $a_{\mathrm{CTX}-\mathrm{M}-1}$, bla $a_{\mathrm{TEM}-104}$, anrA, anrB, dfrA1-orf \\
\hline Fresh poultry organs (liver) & 0126 & AMP, CTX, STR & $b / a_{C T X-M-1}$ \\
\hline $\begin{array}{l}\text { Fresh poultry organs } \\
\text { (gizzard) }\end{array}$ & $\mathrm{O} 20$ & AMC, AMP, STR, T/S & $b / a_{\mathrm{TEM}-1}$ \\
\hline Fresh poultry organs (liver) & 0145 & CAZ, TET & - \\
\hline Frozen poultry meat & $\mathrm{O} 1$ & CTX, NAL, TET & anrA, anrB \\
\hline Frozen poultry meat & 018 & AMC, AMP, STR, TET, T/S & $b l a_{\mathrm{OXA}-1}, b l a_{\mathrm{TEM}-1}$ \\
\hline Frozen poultry & 078 & AMC, AMP, CPD & \\
\hline Frozen poultry meat & 0146 & AMC, AMP, TET, T/S & $b l a_{\mathrm{TEM}-1}$ \\
\hline Frozen organ poultry & 078 & $\begin{array}{l}\text { AMC, AMP, CAZ, CHL, CIP, CRO, CTX, ENR, NAL, STR, } \\
\text { TET, T/S }\end{array}$ & bla $a_{\mathrm{CTX}-\mathrm{M}-14}, b l a_{\mathrm{TEM}-1}$, anrA, anrB, dfrA15 \\
\hline \multicolumn{4}{|l|}{ Beef } \\
\hline Fresh beef meat & 0119 & CPD & - \\
\hline Fresh beef meat & O158 & CPD, TET & - \\
\hline Fresh beef organs (liver) & $\mathrm{O} 78$ & $\begin{array}{l}\text { AMC, AMP, CHL, CIP, CRO, CTX, ENR, NAL, STR, TET, } \\
\text { T/S }\end{array}$ & $b / a_{\mathrm{CTX}-\mathrm{M}-1}, b l a_{\mathrm{TEM}-104}, a n r \mathrm{~A}$, anrB, dfrA1, dfrA1-orf \\
\hline Frozen beef meat & 0103 & STR, TET & $b l a_{\mathrm{CTX}-\mathrm{M}-1}$ \\
\hline Frozen beef meat & 0126 & AMC, AMP, CIP, STR, TET, T/S & $b l a_{\mathrm{TEM}-1}, a n r \mathrm{~A}, a n r \mathrm{~B}$ \\
\hline Frozen beef meat & 0158 & AMC, AMP, STR, TET, T/S & $b / a_{\mathrm{TEM}-1}$ \\
\hline
\end{tabular}

AMC amoxycillin-clavulanic acid, AMP ampicillin, CAZ ceftazidime, CPD cefpodoxime, CRO chloramphenicol, CTX cefotaxime, ENR enrofloxacin, NAL nalidixic acid, STR streptomycin, TET tetracycline, T/S trimethoprim/sulphamethoxazole

A (qnrA), while $3(20.0 \%), 2(13.3 \%)$ and $1(6.7 \%)$ of $S$. enterica serovars possessed qurB, bla $\mathrm{CMY}$ and $q u r \mathrm{~S}$ genes, respectively. $b l a_{\mathrm{OXA}}$ associated with resistance to ampicillin and cephalothin and $b l a_{\mathrm{SHV}}$ associated with plasmid-mediated ampicillin resistance were not found in any isolate.

In $E$. coli isolates, 5 of 8 screened resistance-associated genes were detected by PCR (Table 7). Eleven (52.4\%) out of 21 isolates harboured $b l a_{\text {TEM }}\left(1\right.$ and 104), while $b l a_{\text {CTX- }}$ ${ }_{M}$ (1 and 14) was detected in 9 isolates (42.9\%). Seven isolates (33.3\%) carried qnrA and qnrB and in three isolates (14.3\%) $b l a_{\mathrm{OXA}-1}$ was detected. Genes $b l a_{\mathrm{CMY}}, b l a_{\mathrm{SHV}}$ and $q n r S$ were not detected in any of the $E$. coli isolates.

Plasmid-mediated colistin resistance gene $\mathrm{mcr}-1$ and carbapenemase resistance gene blaOXA-23 were not identified neither in $S$. enterica nor in $E$. coli isolates using PCR assay.

\section{Integron gene cassettes and DNA sequencing}

Class 1 integron was detected in two isolates of $S$. Typhimurium using PCR (Table 6). The inserted gene cassettes identified three types of antimicrobial resistance genes associated with class 1 integron: dihydrofolate reductase types ( $d f r \mathrm{~A} 15$ and $d f r \mathrm{~A} 17)$ which confer resistance to trimethoprim, and aminoglycoside adenyltransferase type $\operatorname{addA} 2$ that confers resistance to streptomycin and spectinomycin.

Three E. coli isolates of serotypes O18, O78 and O78 were harbouring class 1 integron (Table 7). The inserted gene cassettes identified three types of class 1 integron. The identified antimicrobial resistance genes were dihydrofolate reductase types; $d f r \mathrm{~A} 1, d f r \mathrm{~A} 15$ and $d f r \mathrm{~A} 1$-orf which confer resistance to trimethoprim.

All S. enterica and E. coli isolates were negative for class 2 integrons.

\section{Discussion}

Salmonellosis and Salmonella infections considered as critical threats to human and animal health. In this study, the prevalence of $S$. enterica serovars in chicken and beef meat was $8.3 \%$, which was considerably lower than incidence rates that reported in Ethiopia (12.0\% in raw 
meat) [26], Canary islands (16.5\% in chicken meat) [27], Northwestern Spain (17.9\% in chicken) [28], Ethiopia (17.9\% in chicken and giblets) [29], and Egypt (10.0\% in poultry meat) [7]. On the other hand, it was higher than reported previously in meat products in Egypt (6.6\%) and in ground beef in the United States $(4.2 \%)$ [30,31].

In total, $S$. enterica serovar Typhimurium was the dominant serovar. These results were in accordance with previous study from chicken products in Cambodia and Thailand [32]. Controversially, S. enterica serovar Enteritidis was the dominant serotype in imported frozen poultry samples from Brazil to Canary Islands and in chicken carcasses in Spain [27, 28]. Salmonella enterica serovar Kentucky was frequently detected in samples coming from US to Canary Islands [27].

Prevalence of $E$. coli in chicken meat and organs was $16.7 \%$ which was lower than in Nigeria $(43.4 \%)$ in frozen poultry meat [33] but higher than in Korea $(4.9 \%$ in poultry meat) [34]. Prevalence of $E$. coli in beef meat was $6.7 \%$, while in Korea and Iran were found 4.1 and $29.0 \%$, respectively [34, 35].

In this study, $19.0 \%$ of E. coli isolates typed as O78 was mainly from poultry products, while in China, O78 was identified in $60.0 \%$ of $E$. coli isolated from chicken and ducks [36]. E. coli type O158 identified in $9.5 \%$ only in beef meat while $\mathrm{O} 158$ detected in $22.7 \%$ of food isolates in Chile [37].

Bacterial antimicrobial resistance is a global emerging problem of public health concern.

In the current study, a high percentage of S. enterica serovars were resistant to ampicillin and cefotaxime. The resistance to other antimicrobial agents was variable while all isolates were sensitive to chloramphenicol and ciprofloxacin. The results were in a partial accordance with results of previous reports stating that all S. enterica isolated from chicken meat and beef were sensitive to ciprofloxacin [38]. 72.4\% of Salmonella isolates in Thai meat products were resistant to ampicillin while $71.0 \%$ of isolates in Cambodian meat products were resistant to sulfamethoxazole [32]. Controversially, S. enterica isolated from animals and food of animal origin in Italy were highly resistant to ampicillin, chloramphenicol, streptomycin and tetracycline [39] and all Salmonella isolated from beef in Tunisia were susceptible to amoxicillin and clavulanic acid [40].

In total, $46.7 \%$ of S. enterica serovars showed multidrug resistance, which was higher than resistance of Salmonella isolated from raw chicken (31.0\%) in Pennsylvania during [41]. Less multidrug resistant $S$. enterica isolates $(6.0 \%)$ were identified in cattle hides and carcasses in the US [42].

The results of this study showed that the antimicrobial resistance of $E$. coli isolated from poultry was higher than from beef to the most of tested antibiotics. The high resistance to tetracycline, ampicillin, amoxycillinclavulanic acid, trimethoprim/sulphamethoxazole and streptomycin in this study was in agreement with previous reports conducted in Egypt [10, 43] and Algeria [44]. While in Spain, most of E. coli isolated from diarrhoeic and healthy lambs were highly resistant to tetracycline and streptomycin but show lower resistance to ampicillin [45]. Most of $E$. coli isolates in this study were sensitive to enrofloxacin, chloramphenicol and ceftriaxone which is in agreement with previous results in Spain [45].

In this study, $61.9 \%$ of $E$. coli isolates were multidrug resistant. Similar results reported previously in Ghana and US $[23,46]$.

Most of the phenotypically antibiotic resistant $S$. enterica serovars carried antibiotic resistance marker genes associated with $\beta$-lactams and quinolones.

The $\beta$-lactamase encoding gene $b l a_{\text {TEM }}$ conferring resistance to penicillins and first-generation cephalosporins was detected in $73.3 \%$ of S. enterica serovars and in $76.9 \%$ of ampicillin-resistant isolates which is significantly high in comparison to $57.3 \%\left(b l a_{\text {TEM-1 }}\right)$ in S. enterica isolated from retail chickens in China [47]. Another $\beta$-lactamase encoding gene $b l a_{\mathrm{CMY}-2}$, an AmpC betalactamase gene that confers resistance to a wide variety of $\beta$-lactam antibiotics detected in $13.3 \%$ of isolates. In contrast, in $4.7 \%$ of $S$. enterica serovars Typhimurium and Enteritidis originated from diseased broilers in Egypt bla $_{\mathrm{CMY}-2}$ was identified [48] and all resistant S. enterica serovar Typhimurium isolated from retail meat in US were harbouring $b l a_{\mathrm{CMY}}$ [49]. The same gene could not be detected previously in any $S$. enterica serovar Typhimurium isolated from chicken meat in Egypt [8].

$b l a_{\text {CTX-M }}$ could be identified in $73.3 \%$ of isolated $S$. enterica serovars. In 24.0 and $18.8 \%$ of different Salmonella serovars isolated from retail chicken carcasses in China, $b l a_{\mathrm{CTX}-\mathrm{M}-15}$ and $b l a_{\mathrm{CTX}-\mathrm{M}-3}$ were detected, respectively [47].

The $b l a_{\mathrm{SHV}}$ is responsible for the plasmid-mediated ampicillin resistance and $\beta$-lactamase encoding genes $b l a_{\mathrm{OXA}}$ conferring resistance to ampicillin and cephalothin not detected in any of S. enterica serovars in this study. This result was in accordance with a result for $S$. enterica serovar Typhimurium isolated from chicken meat in Egypt [8]. In contrast, 30.2\% of ESBL-producing Salmonella isolated from raw chicken carcasses in China were harbouring $b l a_{\mathrm{OXA}-1}[47]$.

Although none of $S$. enterica serovars were phenotypically resistant to ciprofloxacin, $q n r \mathrm{~A}, q n r \mathrm{~B}$ and $q n r \mathrm{~S}$ genes were detected in 33.3, 20.0 and $6.7 \%$, respectively in all S. enterica serovars and in 100, 60.0 and $20.0 \%$, respectively in S. enterica resistant to nalidixic acid. A different result showed that $1.16 \%$ of nalidixic acid-resistant $S$. 
enterica serovars isolated from animal products in Tunisia carried $q n r$ gene [50]. In other studies in China qnrA, $q n r \mathrm{~B}$ and $q n r \mathrm{~S}$ genes detected with low percentage in $S$. enterica serovar Enteritidis isolated from retail raw poultry $[51,52]$.

The $b l a_{\text {TEM }}$ gene was detected in $52.3 \%$ of all isolated E. coli and in $73.3 \%$ of ampicillin-resistant isolates. Other studies detected $b l a_{\mathrm{TEM}}$ in 97.1 and $75.0 \%$ of $E$. coli isolates from lambs in Spain and meat products in Cambodia, respectively $[32,45]$. In China, $b l a_{\mathrm{TEM}}$ was identified in $7.8 \%$ of ESBL-producing E. coli recovered from meat products [53].

The $\beta$-lactamase encoding gene $b l a_{\mathrm{CMY}}$ was not found in any of the isolated $E$. coli. In contrast, $b l a_{\mathrm{CMY}-2}$ was detected in $89.0 \%$ E. coli isolated from poultry meat in Denmark [54] and in $12.5 \%$ of ESBL-producing E. coli isolated from meat products in Cambodia [32].

The $b l a_{\text {СTX-M }}$ detected in $42.9 \%$ of $E$. coli isolated in this study. In Ghana $50.0 \%$ of ESBL-producing $E$. coli isolates from meat harboured $b l a_{\text {СТХ-М }}$ [46] while these $\beta$-lactamase encoding genes $b l a_{\mathrm{CTX}-\mathrm{M}-15 \text { and }} b l a_{\mathrm{CTX}}$ M-9 were detected rarely (1.6\%) in E. coli isolates from meat products in China [53].

The $b l a_{\mathrm{SHV}}$ gene was not found in any of the E. coli isolates. Controversially, previous studies detected $b l a_{\mathrm{SHV}}$ in 9.4, 5.3 and $2.0 \%$ in meat products in China, broiler chickens and chicken carcasses in Iran, respectively $[53,55,56]$.

$b l a_{\text {OXA-1 }}$ was detected in $14.3 \%$ of the $E$. coli isolates which is in contrast with previous report conducted in retail meat in US where the gene could not be identified [23].

The most common carbapenemase types were blaOXA-23 and blaOXA-48 accounting for $47 \%$ of all identified carbapenemase genes [25, 57]. In this study, blaOXA-23 was not identified in all isolated strains.

In isolated E. coli, qnrA and qnrB detected in $33.3 \%$ of isolates, all nalidixic acid and/or ciprofloxacin resistant isolates harboured both genes. While qnrB and $q n r S$ were identified in $10.4 \%$ of nalidixic acid resistant $E$. coli isolated from Algerian retail chicken meat [44] and in 10.0\% of $E$. coli isolates obtained from bovine carcasses in Mexico [58]. In contrast, qnrA, qrnB and qrnS genes could not be identified in enrofloxacin-resistant $E$. coli strains from poultry in Mexico [59].

The presence of genetic elements such as integrons and transposons are often associated with multi-resistant phenotypes among Salmonella isolates [60]. In this study, class 1 integron detected in $13.3 \%$ of S. enterica serovars. The identified gene cassettes were $d f \mathrm{~A} 15, d f r \mathrm{~A} 17$ and aadA2. In previous studies, class 1 integron identified in 90.0\% of multi-drug resistant Salmonella isolates from retail chicken meat in Japan and the identified genes cassettes were $d f r \mathrm{~A} 1, d f r \mathrm{~A} 7, \operatorname{aad} \mathrm{A} 1, \operatorname{aad} \mathrm{B}$, and $\operatorname{cat} \mathrm{B} 3$ [61,
62]. The gene cassettes of class 1 integron which detected in Salmonella spp. isolated from poultry meat in Egypt were harbouring aac (3)-Id, aadA2, aadA4, aadA7, sat, $d f r \mathrm{~A} 15, \ln u \mathrm{~F}$ and est $\mathrm{X}$ resistance genes [7]. In a study conducted in Portugal, $75.0 \%$ of S. enterica isolated from different sources including food products had one or two class 1 integrons [63].

The identified gene cassettes of class 1 integron $d f r A 1$, $d f r A 15$ and $d f$ rA1-orf which confer resistance to trimethoprim were identified in $14.3 \%$ of $E$. coli isolated in this study. This is in agreement with E. coli isolates from retail chickens in Japan [62] and in 1.9 and $11.4 \%$ of isolates from Thai and Cambodian meat samples obtained from slaughterhouses and fresh markets and the most common gene cassette was $d f \mathrm{~A} 12$-aadA2 [32].

Class 2 integrons were not detected in all isolates of this study which is in contrast to $5.6 \%$ positive samples in Egypt [10].

In this study, $m c r-1$ gene associated with colistin resistance was neither detected in S. enterica nor E. coli isolates. This result was in agreement with the result reported by Doumith et al. [64] who investigated 24,000 isolates of Enterobacteriaceae from food and humans including S. enterica and E. coli and found only $15 \mathrm{mcr}-1$ positive isolates. Recently, Quesada et al. identified the gene $m c r-1$ in nine S. enterica and E. coli isolates from poultry and swine for the first time in Spain [65]. Jayol et al. found the $m c r-1$ in $13 \%$ of $E$. coli and S. enterica [66]. Considering the frequent use of colistin in animal production and the importance of this antimicrobial for the control of multi-resistant Gram-negative nosocomial infections in humans, monitoring the dissemination of resistance to colistin is mandatory.

In conclusion, the results of this study showed high prevalence of S. enterica and E. coli as foodborne pathogens isolated from poultry and beef meat in Egypt. The emergence of antimicrobial resistance of S. enterica and E. coli isolates is of public concerns in Egypt. Significant resistance was detected to penicillin, cephalosporins, tetracycline and sulphonamides. Dissemination of ESBL and AmpC- $\beta$-lactamase resistance-associated genes in $S$. enterica and E. coli was determined. Presence of class 1 integron in S. enterica and E. coli and genes associated with antibiotic resistance was also confirmed. Class 2 integron was not detected in any isolate. Further work should be performed to characterize $S$. enterica and $E$. coli isolates of animal and human origin from the same region sharing the same resistance markers in order to highlight potential horizontal gene transfer by these zoonotic organisms.

\section{Authors' contributions}

AAM participated in the conception and design of the study. AAM performed the farm and laboratory work. AAM, HH, HE, HT, HN and $\mathrm{HMH}$ analyzed the 
data and wrote the manuscript and contributed to manuscript discussion. All authors read and approved the final manuscript.

\section{Author details}

${ }^{1}$ Friedrich-Loeffler-Institut, Institute of Bacterial Infections and Zoonoses, Naumburger Str. 96a, 07743 Jena, Germany. ${ }^{2}$ Bacteriology department, Animal Health Research Institute (AHRI), Mansoura branch, Mansoura, 35516, Egypt.

${ }^{3}$ Faculty of Veterinary Medicine, Kafrelsheikh University, Kafr El-Sheikh 33516, Egypt. ${ }^{4}$ Faculty of Veterinary Medicine, Mansoura University, Mansoura, Egypt. ${ }^{5}$ Institute of Poultry Diseases, Free University Berlin, Berlin, Germany.

\section{Acknowledgements}

The authors thank technical assistants at Kafrelsheikh University for their excellent technical assistance. The authors thank Animal Health Research Institute, Mansoura Laboratory for its great effort in sample collection and preparation.

\section{Competing interests}

The authors declare that they have no competing interests.

\section{Availability of data}

All the data supporting the results presented in the main manuscript.

\section{Consent for publication}

Not applicable.

\section{Ethics approval and consent for participate}

This study was carried out in strict accordance with the recommendations of the, Egyptian Network of Research Ethics Committees (ENREC) which complies with the international laws and regulation regarding ethical considerations in research.

\section{Funding}

This study was done without any specific funding

\section{Publisher's Note}

Springer Nature remains neutral with regard to jurisdictional claims in published maps and institutional affiliations.

Received: 23 June 2017 Accepted: 10 October 2017

Published online: 18 October 2017

\section{References}

1. Helmy Y, El-Adawy H, Abdelwhab E. A comprehensive review of common bacterial, parasitic and viral zoonoses at the human-animal interface in Egypt. Pathogens. 2017;6:33.

2. Pitout J, Laupland K. Extended-spectrum beta-lactamase-producing Enterobacteriaceae: an emerging public-health concern. Lancet Infect Dis. 2008:8:159-66.

3. Bush K, Jacoby GA. Updated functional classification of $\beta$-lactamases. Antimicrob Agents Chemother. 2010;54:969-76.

4. Jacoby GA. AmpC B-lactamases. Clin Microbiol Rev. 2009;22:161-82.

5. Pfeifer Y, Cullik A, Witte W. Resistance to cephalosporins and carbapenems in Gram-negative bacterial pathogens. Int J Med Microbiol. 2010;300:371-9.

6. Abd-Elghany SM, Sallam Kl, Abd-Elkhalek A, Tamura T. Occurrence, genetic characterization and antimicrobial resistance of Salmonella isolated from chicken meat and giblets. Epidemiol Infect. 2015;143:997-1003.

7. Gharieb RM, Tartor $\mathrm{YH}$, Khedr MH. Non-typhoidal Salmonella in poultry meat and diarrhoeic patients: prevalence, antibiogram, virulotyping, molecular detection and sequencing of class I integrons in multidrug resistant strains. Gut Pathog. 2015;7:15-81.

8. Ahmed HA, El-Hofy Fl, Shafik SM, Abdelrahman MA, Elsaid GA. Characterization of virulence-associated genes, antimicrobial resistance genes, and class 1 integrons in Salmonella enterica serovar Typhimurium isolates from chicken meat and humans in Egypt. Foodborne Pathog Dis. 2016;13:281-8
9. Abdallah HM, Reuland EA, Wintermans BB, Al Naiemi N, Koek A, Abdelwahab AM, et al. Extended-spectrum $\beta$-lactamases and/or carbapenemasesproducing Enterobacteriaceae isolated from retail chicken meat in Zagazig, Egypt. PLoS ONE. 2015;10:e0136052.

10. Ahmed AM, Shimamoto T. Molecular analysis of multidrug resistance in Shiga toxin-producing Escherichia coli O157:H7 isolated from meat and dairy products. Int J Food Microbiol. 2015;193:68-73.

11. Andriole VT. The quinolones: past, present, and future. Clin Infect Dis. 2005113-19.

12. Flach CF, Boulund F, Kristiansson E, Larsson DJ. Functional verification of computationally predicted anr genes. Ann Clin Microbiol Antimicrob. 2013;12:34.

13. Guan X, Xue X, Liu Y, Wang J, Wang Y, Wang K, et al. Plasmid-mediated quinolone resistance-current knowledge and future perspectives. J Int Med Res. 2013;41:20-30.

14. Robicsek A, Jacoby GA, Hooper DC. The worldwide emergence of plasmid-mediated quinolone resistance. Lancet Infect Dis. 2006;6:629-40

15. Hanau-Bercot B, Podglajen I, Casin I, Collatz E. An intrinsic control element for translational initiation in class 1 integrons. Mol Microbiol. 2002:44:119-30.

16. Rowe-Magnus DA, Guerout AM, Mazel D. Bacterial resistance evolution by recruitment of super-integron gene cassettes. Mol Microbiol. 2002:43:1657-69.

17. Tzouvelekis L, Markogiannakis A, Piperaki E, Souli M, Daikos G. Treating infections caused by carbapenemase-producing Enterobacteriaceae. Clin Microbiol Infect Dis. 2014;20:862-72.

18. Sun S, Negrea A, Rhen M, Andersson D. Genetic analysis of colistin resistance in Salmonella enterica serovar Typhimurium. Antimicrob Agents Chemother. 2009;53:2298-305.

19. Popoff MY, Bockemuhl J, Gheesling LL. Supplement 2002 (no. 46) to the Kauffmann-White scheme. Res Microbiol. 2004;155:568-70.

20. Bauer AW, Kirby WM, Sherris JC, Turck M. Antibiotic susceptibility testing by a standardized single disk method. Am J Clin Pathol. 1966:45:493-6.

21. CLSI. Performance standards for antimicrobial susceptibility testing; twenty-first informational supplement: CLSI document M100-S21. CLSI. 2011;31:42-51.

22. Maalej S, Meziou M, Rhimi F, Hammami A. Comparison of disc diffusion, Etest and agar dilution for susceptibility testing of colistin against Enterobacteriaceae. Lett Appl Microbiol. 2011;53:546-51.

23. Zhao S, Blickenstaff K, Bodeis-Jones S, Gaines SA, Tong E, McDermott PF. Comparison of the prevalences and antimicrobial resistances of Escherichia coli isolates from different retail meats in the United States, 2002 to 2008. Appl Environ Microbiol. 2012;78:1701-7.

24. Liu Y, Wang Y, Walsh T, Yi LX, Zhang R, Spencer J, et al. Emergence of plasmid-mediated colistin resistance mechanism MCR-1 in animals and human beings in China: a microbiological and molecular biological study. Lancet Infect Dis. 2016;16:161-8.

25. Braun S, Monecke S, Thurmer A, Ruppelt A, Makarewicz O, Pletz M, et al. Rapid identification of carbapenemase genes in gram-negative bacteria with an oligonucleotide microarray-based assay. PLOS ONE. 2014;9:e102232.

26. Ejo M, Garedew L, Alebachew Z, Worku W. Prevalence and antimicrobial resistance of Salmonella isolated from animal-origin food items in Gondar, Ethiopia. Biomed Res Int. 2016;4290506:15-20.

27. Hernandez T, Sierra A, Rodriguez-Alvarez C, Torres A, Arevalo MP, Calvo M, et al. Salmonella enterica serotypes isolated from imported frozen chicken meat in the Canary islands. J Food Prot. 2005;68:2702-6.

28. Capita R, Alonso-Calleja C, Prieto M. Prevalence of Salmonella enterica serovars and genovars from chicken carcasses in slaughterhouses in Spain. J Appl Microbiol. 2007;103:1366-75.

29. Tibaijuka B, Molla B, Hildebrandt G, Kleer J. Occurrence of Salmonellae in retail raw chicken products in Ethiopia. Berl Munch Tierarztl Wochenschr. 2003; 116:55-8

30. Ahmed AM, Shimamoto T. Isolation and molecular characterization of Salmonella enterica, Escherichia coli O157:H7 and Shigella spp. from meat and dairy products in Egypt. Int J Food Microbiol. 2014;169:M405-10.

31. Bosilevac JM, Guerini MN, Kalchayanand N, Koohmaraie M. Prevalence and characterization of salmonellae in commercial ground beef in the United States. Appl Environ Microbiol. 2009;75:1892-900. 
32. Trongjit S, Angkititrakul S, Tuttle RE, Poungseree J, Padungtod P, Chuanchuen R. Prevalence and antimicrobial resistance in Salmonella enterica isolated from broiler chickens, pigs and meat products in Thailand-Cambodia border provinces. Microbiol Immunol. 2017;61:23-33.

33. Adeyanju GT, Ishola O. Salmonella and Escherichia coli contamination of poultry meat from a processing plant and retail markets in Ibadan, Oyo State, Nigeria. Springerplus. 2014;3:139.

34. Lee GY, Jang HI, Hwang IG, Rhee MS. Prevalence and classification of pathogenic Escherichia coli isolated from fresh beef, poultry, and pork in Korea. Int J Food Microbiol. 2009;134:196-200.

35. Momtaz H, Dehkordi FS, Hosseini MJ, Sarshar M, Heidari M. Serogroups, virulence genes and antibiotic resistance in Shiga toxin-producing Escherichia coli isolated from diarrheic and non-diarrheic pediatric patients in Iran. Gut Pathog. 2013;5:1757-4749.

36. Wang S, Meng Q, Dai J, Han X, Han Y, Ding C, et al. Development of an allele-specific PCR assay for simultaneous sero-typing of avian pathogenic Escherichia coli predominant $\mathrm{O1}, \mathrm{O} 2, \mathrm{O} 18$ and $\mathrm{O} 78$ strains. PLOS ONE. 2014:9:e96904.

37. Alexandre M, Prado V, Ulloa MT, Arellano C, Rios M. Detection of enterohemorrhagic Escherichia coli in meat foods using DNA probes, enzymelinked immunosorbent assay and polymerase chain reaction. J Vet Med B Infect Dis Vet Public Health. 2001:48:321-30.

38. Larkin C, Poppe C, McNab B, McEwen B, Mahdi A, Odumeru J. Antibiotic resistance of Salmonella isolated from hog, beef, and chicken carcass samples from provincially inspected abattoirs in Ontario. J Food Prot. 2004;67:448-55.

39. Perugini AG, Carullo MR, Esposito A, Caligiuri V, Capuano F, Galiero G, et al. Characterization of antimicrobial resistant Salmonella enterica serovars Enteritidis and Typhimurium isolates from animal and food in Southern Italy. Vet Res Commun. 2010;34:387-92.

40. Oueslati W, Rjeibi MR, Mhadhbi M, Jbeli M, Zrelli S, Ettriqui A. Prevalence, virulence and antibiotic susceptibility of Salmonella spp. strains, isolated from beef in Greater Tunis (Tunisia). Meat Sci. 2016;119:154-9.

41. M'lkanatha NM, Sandt CH, Localio AR, Tewari D, Rankin SC, Whichard $J M$, et al. Multidrug-resistant Salmonella isolates from retail chicken meat compared with human clinical isolates. Foodborne Pathog Dis. 2010;7:929-34.

42. Brichta-Harhay DM, Arthur TM, Bosilevac JM, Kalchayanand N, Shackelford SD, Wheeler TL, et al. Diversity of multidrug-resistant Salmonella enterica strains associated with cattle at harvest in the United States. Appl Environ Microbiol. 2011;77:1783-96.

43. Ahmed AM, Shimamoto T, Shimamoto T. Molecular characterization of multidrug-resistant avian pathogenic Escherichia coli isolated from septicemic broilers. Int J Med Microbiol. 2013;303:475-83.

44. Laarem M, Barguigua A, Nayme K, Akila A, Zerouali K, El Mdaghri N, et al. Occurrence of plasmid-mediated quinolone resistance and virulence genes in avian Escherichia coli isolates from Algeria. J Infect Dev Ctries. 2017;11:143-51.

45. Medina A, Horcajo P, Jurado S, De la Fuente R, Ruiz-Santa-Quiteria JA, Dominguez-Bernal G, et al. Phenotypic and genotypic characterization of antimicrobial resistance in enterohemorrhagic Escherichia coli and atypical enteropathogenic E. coli strains from ruminants. J Vet Diagn Investig. 2011;23:91-5.

46. Rasmussen MM, Opintan JA, Frimodt-Moller N, Styrishave B. Betalactamase producing Escherichia coli isolates in imported and locally produced chicken meat from Ghana. PLoS ONE. 2015;10:e0139706.

47. Qiao J, Zhang Q, Alali WQ, Wang J, Meng L, Xiao Y, et al. Characterization of extended-spectrum $\beta$-lactamases (ESBLs)-producing Salmonella in retail raw chicken carcasses. Int J Food Microbiol. 2017;248:72-81.

48. Ahmed AM, Shimamoto T. Genetic analysis of multiple antimicrobia resistance in Salmonella isolated from diseased broilers in Egypt. Microbiol Immunol. 2012;56:254-61.

49. Folster JP, Tolar B, Pecic G, Sheehan D, Rickert R, Hise K, et al. Characterization of blaCMY plasmids and their possible role in source attribution of Salmonella enterica serotype Typhimurium infections. Foodborne Pathog Dis. 2014;11:301-6.

50. Al-Gallas N, Abbassi MS, Gharbi B, Manai M, Ben Fayala MN, Bichihi R, et al. Occurrence of plasmid-mediated quinolone resistance determinants and $r m t$ B gene in Salmonella enterica serovar Enteritidis and Typhimurium isolated from food-animal products in Tunisia. Foodborne Pathog Dis. 2013;10:813-9.

51. Wang Y, Yang B, Wu Y, Zhang Z, Meng X, Xi M, et al. Molecular characterization of Salmonella enterica serovar Enteritidis on retail raw poultry in six provinces and two National cities in China. Food Microbiol. 2015;46:74-80.

52. Zhang $Z$, Meng $X$, Wang $Y, X i a X$, Wang $X$, Xi M, et al. Presence of qnr $\operatorname{aac}\left(6^{\prime}\right)-1 b, q e p A, o q \times A B$, and mutations in gyrase and topoisomerase in nalidixic acid-resistant Salmonella isolates recovered from retail chicken carcasses. Foodborne Pathog Dis. 2014;11:698-705.

53. Li L, Ye L, Kromann S, Meng H. Occurrence of extended-spectrum B-lactamases, plasmid-mediated quinolone resistance, and disinfectant resistance genes in Escherichia coli isolated from ready-to-eat meat products. Foodborne Pathog Dis. 2017;14:109-15.

54. Hansen KH, Bortolaia V, Nielsen CA, Nielsen JB, Schonning K, Agerso Y, et al. Host-specific patterns of genetic diversity among Incl1-Igamma and IncK plasmids encoding CMY-2 B-lactamase in Escherichia coli isolates from humans, poultry meat, poultry, and dogs in Denmark. Appl Environ Microbiol. 2016;82:4705-14.

55. Jafari RA, Motamedi H, Maleki E, Ghanbarpour R, Mayahi M. Phylogenetic typing and detection of extended-spectrum B-lactamases in Escherichia coli isolates from broiler chickens in Ahvaz, Iran. Vet Res Forum. 2016;7:227-33

56. Bagheri M, Ghanbarpour R, Alizade H. Shiga toxin and beta-lactamases genes in Escherichia coli phylotypes isolated from carcasses of broiler chickens slaughtered in Iran. Int J Food Microbiol. 2014;177:16-20.

57. Kaase M. Carbapenemases in gram-negative bacteria. Current data and trends of resistance resulting from the work of national reference centres. Bundesgesundheitsbl Gesundheitsforsch Gesundheitsschutz 2012;55:1401-4.

58. de Oca SAM, Talavera-Rojas M, Soriano-Vargas E, Barba-Leon J, VazquezNavarrete J. Determination of extended spectrum $\beta$-lactamases/AmpC B-lactamases and plasmid-mediated quinolone resistance in Escherichia coli isolates obtained from bovine carcasses in Mexico. Trop Anim Health Prod. 2015;47:975-81.

59. Del Rio-Avila C, Rosario C, Arroyo-Escalante S, Carrillo-Casas EM, DiazAparicio E, Suarez-Guemes F, et al. Characterisation of quinolone-resistant Escherichia coli of 1997 and 2005 isolates from poultry in Mexico. Br Poult Sci. 2016;57:494-500.

60. Guerra B, Soto S, Helmuth R, Mendoza MC. Characterization of a selftransferable plasmid from Salmonella enterica serotype Typhimurium clinical isolates carrying two integron-borne gene cassettes together with virulence and drug resistance genes. Antimicrob Agents Chemother 2002:46:2977-81.

61. Ahmed AM, Ishida Y, Shimamoto T. Molecular characterization of antimicrobial resistance in Salmonella isolated from animals in Japan. J Appl Microbiol. 2009;106:402-9.

62. Ahmed AM, Shimabukuro H, Shimamoto T. Isolation and molecular characterization of multidrug-resistant strains of Escherichia coli and Salmonella from retail chicken meat in Japan. J Food Sci. 2009;74:1750-3841.

63. Antunes $P$, Machado J, Peixe L. Characterization of antimicrobial resistance and class 1 and 2 integrons in Salmonella enterica isolates from different sources in Portugal. J Antimicrob Chemother. 2006;58:297-304.

64. Doumith M, Godbole G, Ashton P, Larkin L, Dallman T, Day M, et al. Detection of the plasmid-mediated $\mathrm{mcr}$-1 gene conferring colistin resistance in human and food isolates of Salmonella enterica and Escherichia coli in England and Wales. J Antimicrob Chemother. 2016;71:2300-5.

65. Quesada A, Ugarte-Ruiz M, Iglesias M, Porrero M, Martinez R, Florez-Cuadrado $D$, et al. Detection of plasmid mediated colistin resistance (MCR-1) in Escherichia coli and Salmonella enterica isolated from poultry and swine in Spain. Res Vet Sci. 2016;105:134-5.

66. Jayol A, Nordmann P, Lehours P, Poirel L, Dubois V. Comparison of methods for detection of plasmid-mediated and chromosomally encoded colistin resistance in Enterobacteriaceae. Clin Microbiol Infect Dis. 2017;:S1198-743X:30291-4.

67. Seidavi A, Mirhosseini SZ, Shivazad M, Chamani M, Sadeghi AA, Pourseify R. Detection and investigation of Escherichia coli in contents of duodenum, jejunum, ileum and cecum of broilers at different ages by PCR. Asia-Pac J Mol Biol Biotechnol. 2010;18:321-6. 
68. Alvarez J, Sota M, Vivanco AB, Perales I, Cisterna R, Rementeria A, et al. Development of a multiplex PCR technique for detection and epidemiological typing of Salmonella in human clinical samples. J Clin Microbiol. 2004:42:1734-8.
69. Ahmed AM, Motoi Y, Sato M, Maruyama A, Watanabe H, Fukumoto Y, et al. Zoo animals as reservoirs of gram-negative bacteria harboring integrons and antimicrobial resistance genes. Appl Environ Microbiol. 2007;73:6686-90.
Submit your next manuscript to BioMed Central and we will help you at every step:

- We accept pre-submission inquiries

- Our selector tool helps you to find the most relevant journal

- We provide round the clock customer support

- Convenient online submission

- Thorough peer review

- Inclusion in PubMed and all major indexing services

- Maximum visibility for your research

Submit your manuscript at www.biomedcentral.com/submit
() Biomed Central 